Artigo

\title{
Sala de aula invertida adaptada ao ensino remoto: uma proposta de ensino híbrido aplicado à Análise Combinatória
}

\author{
Flipped classroom adapted to remote education: a hybrid teaching proposal applied to \\ Combinatorial Analysis
}

Aula invertida adaptada a la enseñanza remota: una propuesta didáctica híbrida aplicada al Análisis Combinatorio

\author{
Brunna Seadi Lima Marques ${ }^{1}$ \\ (D) [0000-0001-5858-0130] \\ Nelson Machado Barbosa ${ }^{2}$ \\ [0000-0002-0628-1195]
}

\begin{abstract}
Resumo
Visando promover um ensino mais eficiente e de qualidade neste período de pandemia, este artigo apresenta uma adaptação de uma metodologia Ativa denominada Ensino Híbrido, em particular, o modelo Sala de Aula Invertida. Buscou-se desta forma, enriquecer a prática pedagógica por meio de uma abordagem metodológica inédita com o uso integrado das tecnologias digitais, visando a personalização do Ensino Remoto por meio de uma Sequência Didática aplicada em uma turma do 2은 ano do ensino médio de uma instituição privada do Estado do Rio de Janeiro. A pesquisa é de caráter quantitativo e qualitativo e os dados foram coletados buscando investigar o desempenho e as reações dos estudantes em meio aos conceitos da Análise Combinatória. Os resultados mostraram que a Sala de Aula Invertida Adaptada ao Ensino Remoto pode, de fato, contribuir para a aprendizagem do tema proposto neste período de isolamento social, podendo ser destacadas como principais contribuições o desenvolvimento da autonomia e senso crítico bem como a capacidade argumentativa e socializadora dos estudantes.
\end{abstract}

Palavras-chave: Ensino híbrido. Sala de Aula Invertida Adaptada. Análise Combinatória.

\begin{abstract}
In order to promote more efficient and quality education in this period of pandemic, this article presents an adaptation of an Active methodology called Hybrid Teaching, in particular, the Flipped Classroom model. In this way, it was sought to enrich the pedagogical practice through an unprecedented methodological approach with the integrated use of digital technologies aiming at the personalization of Remote Teaching through a Didactic Sequence applied to a 2nd year high school class at a private institution in the State of Rio de Janeiro. The research is quantitative and qualitative, where the data collected sought to investigate the performance and reactions of students amid the concepts of Combinatorial Analysis. The results showed that the Flipped Classroom Adapted to Remote Education can, in fact, contribute to the learning of the theme proposed in this period of social isolation, with the development of autonomy and critical sense as well as the argumentative and socializing capacity of the students.
\end{abstract}

\footnotetext{
${ }^{1}$ brunnaseadi@gmail.com, Mestra em Matemática, Programa de Pós-Graduação Profissional em Matemática, Universidade Estadual do Norte Fluminense, Campos dos Goytacazes/RJ/Brasil. 2 barbosa@uenf.br, Doutor em Modelagem Computacional, Professor Associado, Universidade Estadual do
Norte Fluminense, Campos dos Goytacazes/RJ/Brasil.
} 
Keywords: Hybrid teaching. Adapted Flipped Classroom. Combinatory Analysis.

\section{Resumen}

Con el fin de promover una educación más eficiente y de calidad en este período pandémico, este artículo presenta una adaptación de una metodología Activa denominada Enseñanza Híbrida, en particular, el modelo de Aula Invertida. De esta manera, se buscó enriquecer la práctica pedagógica através de un enfoque metodológico inédito con el uso integrado de tecnologías digitales, con miras a la personalización de la Educación Remota através de una Secuencia Didáctica aplicado a una clase de segundo año de secundaria en una institución privada en el estado de Río de Janeiro. La investigación es de carácter cuantitativo y cualitativo y los datos fueron recolectados con el fin de investigar el desempeño y reacciones de los estudiantes en medio de los conceptos del Análisis Combinatorio. Los resultados mostraron que el Aula Invertida Adaptada a la Educación Remota puede, de hecho, contribuir al aprendizaje de la temática propuesta en este período de aislamiento social, con el desarrollo de la autonomía y el sentido crítico así como el argumentativo y socialización de estudiantes.

Palabras claves: Enseñanza híbrida. Aula Invertida Adaptada. Análisis Combinatorio.

\section{Introdução}

Esta pesquisa foi desenvolvida com objetivo de tornar o ensino-aprendizagem da Análise Combinatória mais eficiente, incorporando ferramentas tecnológicas que são tão difundidas na sociedade pela construção do conhecimento dos processos de contagem, por meio da aplicação de Metodologias Ativas de aprendizagem, que são "estratégias pedagógicas que colocam o foco do processo de ensino e aprendizagem no aprendiz, contrastando com a abordagem pedagógica do ensino tradicional, centrada no professor, que transmite informação aos alunos" (VALENTE; ALMEIDA; GERALDINI, 2017, p. 463). Para absorver as tecnologias digitais de informação e comunicação (TDICs) no processo de ensinoaprendizagem desses conceitos, foi definida a utilização da metodologia ativa denominada Ensino Híbrido, adotando a estratégia da Sala de Aula Invertida. Christensen, Horn e Staker (2013, p.7), definem o Ensino Híbrido como,

Um programa de educação formal no qual o estudante aprende, pelo menos em parte, por meio do ensino online, com algum elemento de controle do discente sobre o tempo, lugar, modo e/ou ritmo do estudo, e pelo menos em parte em uma localidade física supervisionada, fora de sua residência. (CHRISTENSEN; HORN; STAKER, 2013, p. 7).

Nesse contexto, a Sala de Aula Invertida é o modelo no qual inverte-se a forma tradicional de ensino, ou seja, "o conteúdo e as instruções são estudados on-line antes do aluno frequentar a sala de aula, que agora passa a ser o local para trabalhar os conteúdos já estudados, realizando atividades práticas como resolução de problemas e projetos, discussão em grupo, laboratórios" (VALENTE, 2014, p. 85).

A experimentação da presente pesquisa ocorreu no primeiro trimestre letivo do ano de 2020, em um cenário de pandemia global ocasionado pelo novo coronavírus, o chamado SARS-CoV-2, causador da doença COVID-19. Diante disso, a continuidade do ano letivo foi determinada pelas autoridades competentes com objetivo de atenuar as perdas educacionais, recorrendo às TDICs para permitir a comunicação entre as instituições de ensino, professores e alunos. Em primeiro momento, no dia 18 de março de 2020, o Conselho Nacional de Ensino 
(CNE) editou uma Nota de esclarecimento autorizando a realização de atividades a distância na Educação Básica (BRASIL, 2020a), em seguida, o Conselho Estadual de Educação do Estado do Rio de Janeiro (CEE-RJ) publicou a Deliberação no 376 orientando as instituições de ensino a respeito das atividades escolares não presenciais em caráter excepcional (RIO DE JANEIRO, 2020), e ainda, no dia 01얼 de junho de 2020, foi publicada o Parecer CNE/CP no 05/2020 com informações a respeito da reorganização dos calendários escolares e o ensino remoto (BRASIL, 2020b).

A principal adaptação sugerida nesta pesquisa para execução do Ensino Híbrido na modalidade Sala de Aula Invertida nesse contexto excepcional é a utilização de aulas ao vivo por videoconferência (aprendizagem síncrona) ao invés dos encontros presenciais, para esclarecer as dúvidas dos alunos e desenvolver as atividades. A aprendizagem assíncrona é desenvolvida por intermédio das videoaulas elaboradas pelos pesquisadores e disponibilizadas na plataforma de ensino adotada pela escola, trazendo autonomia e flexibilidade para o processo de construção do saber do aluno. Sendo assim, esta pesquisa foi desenvolvida buscando responder a seguinte questão: como o Ensino Híbrido, em particular a Sala de aula Invertida, pode auxiliar no processo de ensino-aprendizagem da teoria da Análise Combinatória para os alunos da 2a série do Ensino Médio, considerando o contexto do Ensino Remoto? Levando em conta essa questão de pesquisa, o objetivo precípuo deste trabalho é a implementação do Ensino Híbrido por meio da estratégia Sala de Aula Invertida adaptada ao Ensino Remoto no processo de ensino-aprendizagem da Análise Combinatória, em uma turma da 2a série do Ensino Médio da Escola Positiva, localizada em Barra de São João, segundo distrito do município de Casimiro de Abreu no interior do Estado do Rio de Janeiro. Para isso, delimitou-se os seguintes objetivos específicos:

- Promover estudos e pesquisas sobre a Análise Combinatória;

- Fomentar a utilização das TDICs como ferramenta de ensino, sobretudo a videoaula;

- Suscitar pesquisas sobre as Metodologias Ativas, o Ensino Híbrido e a Sala de Aula Invertida;

- Estimular os alunos a desenvolver autonomia na construção do conhecimento;

- Desenvolver uma Sequência Didática para ensino da Análise Combinatória utilizando a estratégia Sala de Aula Invertida;

- Coletar dados por meio da observação do desempenho dos alunos nas aulas síncronas, nas atividades propostas e na aplicação de questionário;

- Analisar a eficácia da Sala de Aula Invertida Adaptada para o Ensino Remoto visando o ensino e aprendizagem da Análise Combinatória.

Para alcançar os objetivos propostos, esta pesquisa se baseou na aplicação inédita da Metodologia Ativa adaptada ao Ensino Remoto. Além disso, foi desenvolvida uma pesquisa aplicada de caráter exploratório por intermédio da abordagem mista, ou seja, qualitativa e quantitativa, para análise dos resultados obtidos ao desenvolver uma intervenção pedagógica. Por meio dessa análise, percebeu-se que a metodologia proposta contribuiu significativamente para o aprendizado dos conceitos da Análise Combinatória.

\section{Ensino Híbrido: a Sala de Aula Invertida Adaptada ao Ensino Remoto}

Pode-se entender o conceito de Ensino Híbrido como a fusão do ensino clássico com o ensino on-line; ele traz a ideia de que a sala de aula tradicional é apenas um dos espaços em que o processo de ensino-aprendizagem ocorre, pois, empregando as ferramentas digitais, a educação pode ser implementada de forma continuada, permitindo que o aluno tenha 
contato com o conteúdo a qualquer hora e em qualquer lugar, desde que ele tenha acesso aos instrumentos adotados.

Com a aplicação dessa metodologia, o aluno ganha mais autonomia na construção do saber e ao encontrar o professor, a aula torna-se mais fluida e mais interativa, uma vez que o primeiro contato com o conteúdo ocorre por meio das TDICs, previamente à aula.

Do ponto de vista do professor, ele deixa de ser orador e passa a ser facilitador: nesse contexto, o professor não apresentará o conteúdo em uma aula expositiva, mas a partir do desenvolvimento de diversas atividades, ele se certifica se os alunos compreenderam o que foi exposto no material previamente disponibilizado, e faz as devidas ponderações acerca do assunto. Os modelos de Ensino Híbrido trazidos por Christensen, Horn e Staker (2013), são: Modelo de Rotação, Modelo Flex, Modelo A La Carte e o Modelo Virtual Enriquecido. Nesta pesquisa será utilizado o Modelo de Rotação; nesta modalidade os alunos rotacionam em diversas outras modalidades de ensino que podem incluir resoluções de exercícios, estudos de caso, jogos, estudos dirigidos, dentre outras, desenvolvidas de forma individual ou coletiva, de acordo com a preferência do professor, mantendo pelo menos uma modalidade on-line. 0 modelo de Rotação tem quatro sub-modelos: Rotação por Estações, Laboratório Rotacional, Sala de Aula Invertida, e Rotação Individual. Esta pesquisa adotou o submodelo Sala de Aula Invertida. A definição de Sala de Aula Invertida, de acordo com Bergmann e Sams (2016), é fazer em casa o que tradicionalmente era feito em aula e em aula o trabalho que era feito em casa. Nesse contexto, a ideia dessa metodologia é que o aluno tenha contato prévio com o conteúdo mediante a disponibilização de materiais em uma plataforma de comunicação e a sala de aula se torna um ambiente de prática, por meio de discussões e desenvolvimento de atividades individuais e coletivas. A Figura 1 traz uma comparação entre o método tradicional de ensino e a Sala de Aula Invertida.

Figura 1 - Comparativo entre o Modelo Tradicional de Ensino e a Sala de Aula Invertida.
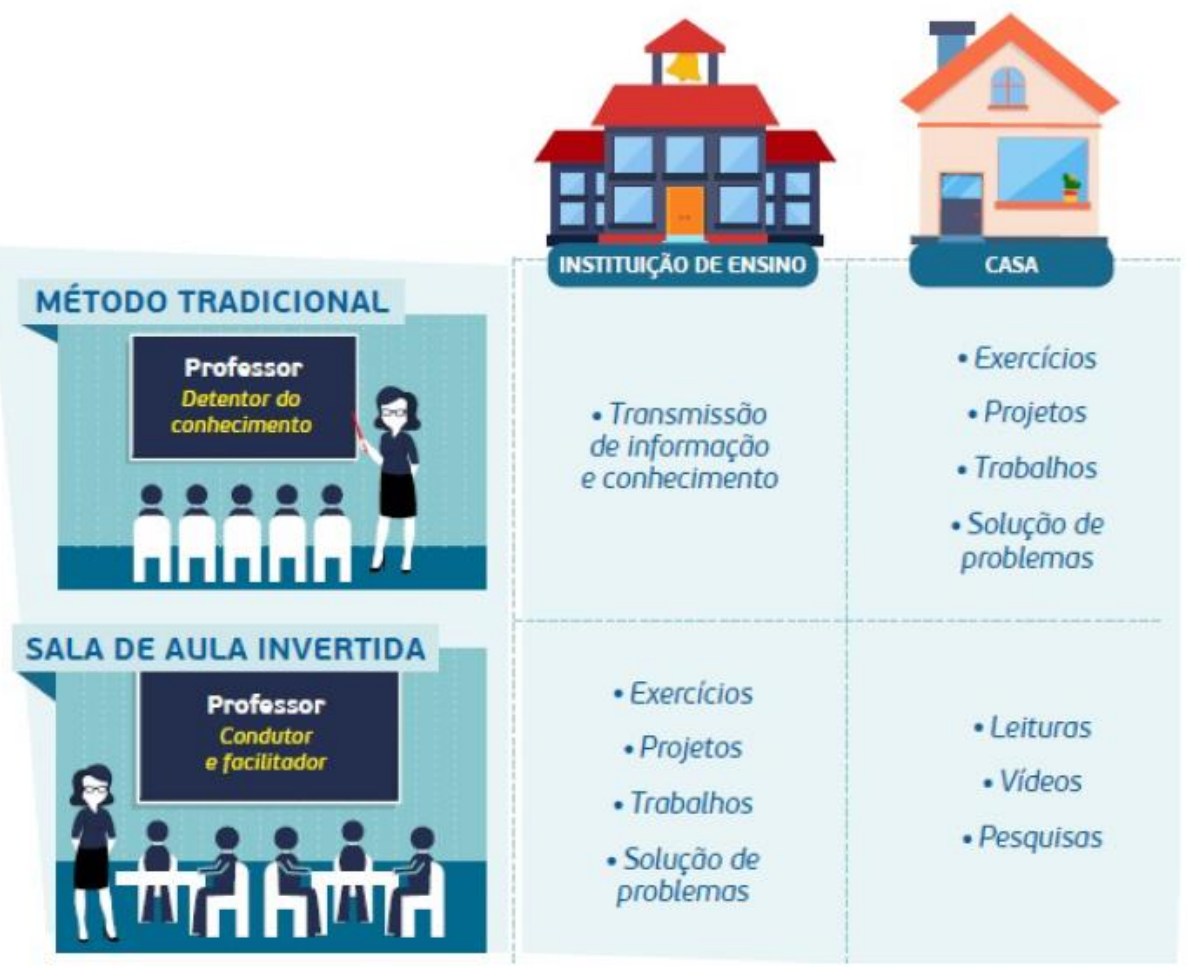

Fonte: (Aranha; Feferbaum, 2015, p. 16). 
A Sala de Aula Invertida tem a intenção de colocar o aluno no centro do processo de ensino-aprendizagem; para exercer o protagonismo exigido nesse método, é necessário que o aluno seja orientado quanto à forma de se planejar, garantindo que haverá contato com o conteúdo antes da aula presencial, e de estudar, tomando nota do que é preciso esclarecer. A esse respeito, Schmitz (2016) afirma que "é preciso preparar os alunos para fazerem anotações e registrarem dúvidas para que, em aula, os professores possam trabalhar controvérsias e equívocos" (SCHMITZ, 2016, p. 38). Em relação as habilidades envolvidas na metodologia Sala de Aula Invertida, Schmitz (2016) elaborou uma imagem que sintetiza esse processo (Figura 2). A autora mostra que, antes da aula, o professor vai trabalhar com os alunos as habilidades cognitivas relacionadas à compreender e recordar o conteúdo, recorrendo ao material disponibilizado; durante a aula, o objetivo é aplicar, analisar, avaliar e criar a partir do conhecimento adquirido; e, por fim, depois da aula todas essas habilidades podem ser trabalhadas mediante à revisão de conceitos e do desenvolvimento de tarefas (SCHMITZ, 2016, p. 67). A imagem também mostra as principais habilidades socioemocionais desenvolvidas com essa metodologia, a saber: antes da aula destaca-se a necessidade de motivação, autonomia e perseverança; durante a aula, o autocontrole, a resiliência e a colaboração; e a qualquer momento, a comunicação e a criatividade (SCHMITZ, 2016, p. 67).

Figura 2 - Estrutura básica da metodologia Sala de Aula Invertida.

\section{SALA DE AULA INVERTIDA}

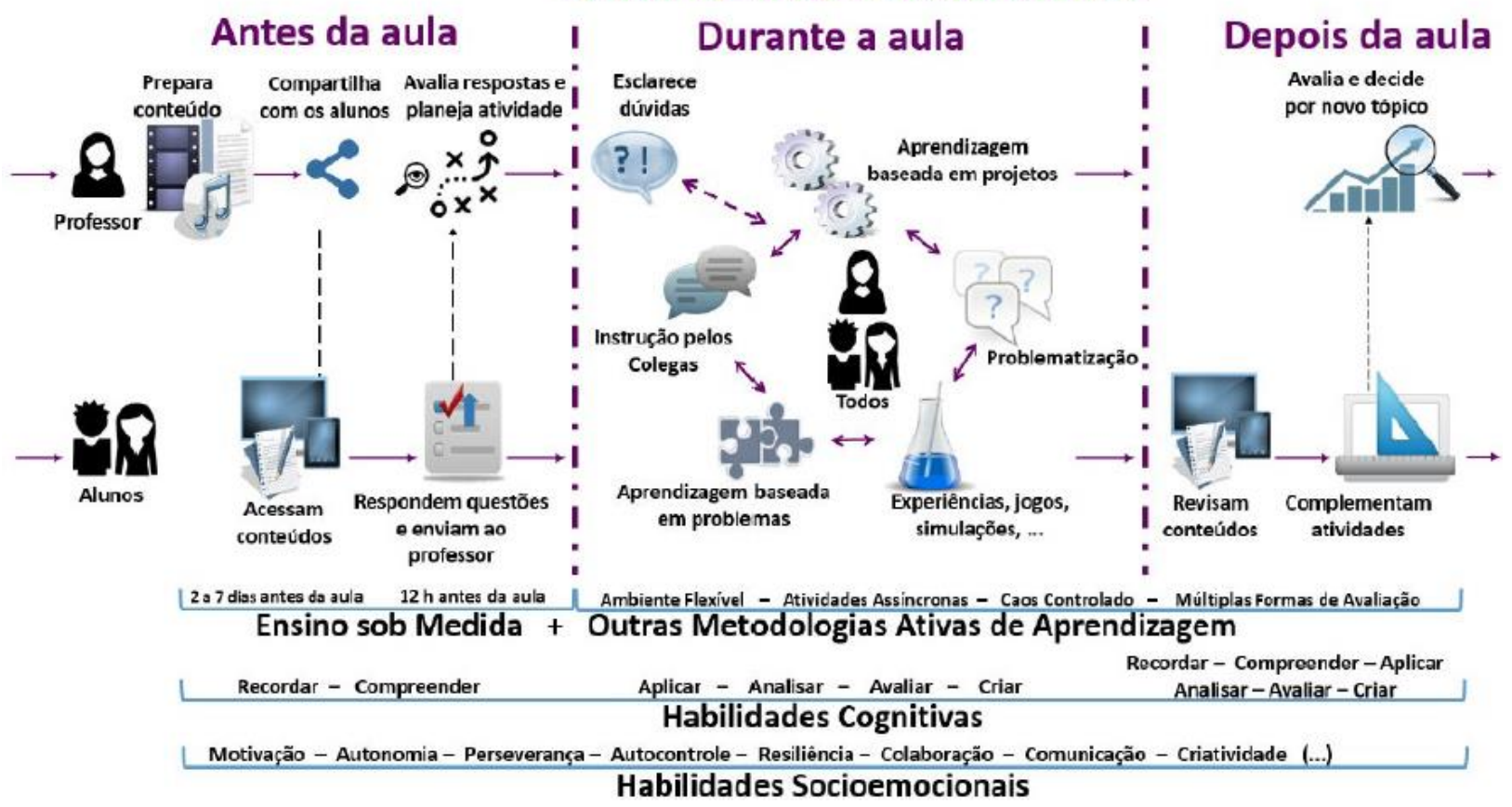

Fonte: (Schmitz, 2016, p.67).

Nesse contexto, a Revista Ei! Ensino Inovativo da Fundação Getúlio Vargas (FVG), elenca os principais benefícios da implementação da Sala de Aula Invertida, a saber: fornece mais autonomia ao discente e exige dele maior senso de responsabilidade, uma vez que ele é o centro do processo de aprendizagem; promove aos alunos e aos professores maior facilidade de identificar os fragmentos do conteúdo que não foram compreendidos; permite que a discussão sobre conteúdo seja aprofundada, já que os alunos chegam em sala de aula com conhecimento prévio do assunto (ARANHA; FEFERBAUM, 2015, p. 15). 
Ocorre que, em decorrência da pandemia causada pelo novo coronavírus (SARS-CoV2), visando minimizar os prejuízos no âmbito educacional, o Ensino Remoto foi estabelecido em muitos países do mundo, inclusive no Brasil. Dessa forma, a metodologia de ensinoaprendizagem adotada pelos professores teve que ser adaptada à nova realidade educacional. Muitos fatores precisaram ser levados em consideração, tais como: a disponibilidade de computadores (celulares ou tablets); Internet para os professores e para os alunos; o acesso à outras ferramentas pelos professores, como quadros, mesas digitalizadoras, suportes para celulares, etc.; a disponibilidade de ambiente apropriado para trabalho/estudo dentro da realidade domiciliar de cada indivíduo; a disponibilidade de uma plataforma para comunicação da tríade educacional professor/aluno/instituição; dentre outros diversos fatores físicos, além de questões psicológicas e emocionais relacionadas a essa nova perspectiva.

Assim, esta pesquisa propõe a aplicação da Sala de Aula Invertida Adaptada ao Ensino Remoto. A adaptação desse modelo foi necessária diante da atual circunstância de isolamento social. Cabe ressaltar que o Ensino Híbrido emerge como uma estratégia alternativa ao ensino tradicional. Para isso, esta pesquisa propõe a flexibilização do Ensino Remoto em dois momentos, a saber: aprendizagem síncrona - com o professor e os alunos ao vivo, por meio de uma plataforma de videoconferência; aprendizagem assíncrona - com a disponibilização de materiais em um ambiente virtual de aprendizagem. A Figura 3 traz a definição de Ensino Híbrido trazida por Christensen, Horn e Staker (2013), e a forma de adaptação ao Ensino Remoto proposta nesta pesquisa.

Figura 3 - Definição do Ensino Híbrido e a adaptação ao Ensino Remoto.

\section{O ensino híbrido é um programa de educação formal no qual um estudante aprende:}

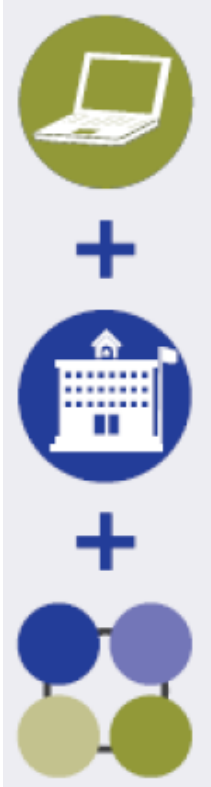

pelo menos em parte por meio do ensino online, com algum elemento de controle do aluno sobre o tempo, local, caminho e/ou ritmo do aprendizado;

pelo menos em parte em uma localidade física supervisionada, fora de sua residência;

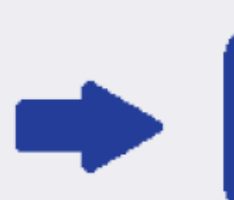

No ensino remoto, essa etapa ocorre nas aulas ao vivo por meio das videoconferências que conectam os alunos e o professor.

e que as modalidades ao longo do caminho de aprendizado de cada estudante em um curso ou matéria estejam conectados, oferecendo uma experiência de educaçáo integrada.

Fonte: Adaptado de Christensen, Horn e Staker ( 2013, p. 8).

Sendo assim, apesar dos encontros presenciais terem ganhado um novo significado na pandemia (as aulas ao vivo), por meio das TDICs foi possível criar um ambiente coletivo de ensino-aprendizagem, desenvolver atividades e promover discussões. As plataformas de 
videoconferência permitem que os usuários utilizem câmeras, microfones, chats, além de possibilitarem a apresentação da tela do computador do anfitrião, viabilizando que ele transmita aos demais usuários slides, vídeos, simuladores, e todas as demais ferramentas que ele queira utilizar como recurso pedagógico.

Dentre os modelos de Ensino Híbrido, a Sala de Aula Invertida é caracterizada por Valente $(2014$, p.86) como a abordagem "em que o aluno estuda antes da aula e a aula se torna o lugar de aprendizagem ativa, onde há perguntas, discussões e atividades práticas". Segundo Bergmann e Sams (2016),

\begin{abstract}
Adotar as ferramentas tecnológicas e o ensino assíncronico, que caracterizam a sala de aula invertida, com uma abordagem voltada para os alunos, para decidir o que lecionar, tende a criar um ambiente estimulante para a curiosidade. Não se precisa mais perder tempo reapresentando conceitos já bem conhecidos, que apenas devem ser relembrados, nem usar o valioso tempo em sala de aula para transmitir novo conteúdo. (BERGMANN; SAMS, 2016, p. 45).
\end{abstract}

Para utilizar essa estratégia de Ensino Híbrido adaptado ao Ensino Remoto, a presente pesquisa propõe o seguinte desenvolvimento: na chamada aprendizagem assíncrona, os pesquisadores disponibilizam as videoaulas em um ambiente virtual de aprendizagem que contenham os conceitos relacionados àquele conteúdo que deseja transmitir, e o aluno poderá acessá-los a qualquer momento previamente ao encontro ao vivo; a adaptação ocorre na denominada aprendizagem síncrona, já que o professor utilizará as aulas ao vivo para identificar as lacunas existentes no entendimento do conteúdo, responder as indagações, esclarecer as dúvidas dos alunos e desenvolver as atividades pertinentes. É necessário pontuar que a escolha das videoaulas como instrumento de transmissão do conhecimento na aprendizagem assíncrona deste trabalho é baseada na riqueza de recursos que essa ferramenta proporciona, o que assemelha da explicação usual do professor em sala de aula e no desenvolvimento do processo de aprendizagem unindo os sentidos da audição e da visão do aluno, recorrendo a junção de imagens, escritas, sons e vozes.

Apesar da abordagem da Sala de Aula Invertida ser classificada por Christensen, Horn e Staker (2013) como uma inovação sustentada, é válido destacar que no contexto do Ensino Remoto essa inovação traz características de ambas as formas de inovação. Do ponto de vista da inovação sustentada, essa metodologia conserva principalmente os atributos de atingir os alunos já matriculados na escola e de não trazer um modelo mais simples que o sistema préexistente; por outro lado, do ponto de vista da inovação disruptiva, ela preserva poucas características em relação à sala de aula tradicional, trazendo uma mudança mais abrupta ao processo de ensino-aprendizagem. Sobre esse aspecto, os autores afirmam que,

Definir se algo é disruptivo ou sustentado é importante porque, no final, as disrupções quase sempre se tornam boas o suficiente para atender às necessidades dos clientes tradicionais, que as adotam encantados com as novas propostas de valor que elas oferecem. Em outras palavras, os modelos disruptivos quase sempre suplantam os modelos sustentados no longo prazo. (CHRISTENSEN; HORN; STAKER, 2013, p. 26).

As vantagens trazidas pela Sala de Aula Invertida já discutidas anteriormente tornamse ainda mais relevantes ao adotar essa estratégia durante o Ensino Remoto, a saber: 
- Os materiais fornecidos na aprendizagem assíncrona com os conceitos abordados pelo professor formam um banco de dados que poderá ser acessado pelo estudante a qualquer momento, minimizando os impactos causados pelo Ensino Remoto;

-Diante de tantas mudanças em sua rotina, o aluno tem a oportunidade de escolher o melhor momento para acessar o material disponibilizado pelo professor e aprender um novo conceito matemático;

- A aprendizagem síncrona fica mais dinâmica, possibilitando uma vivência mais fluida e leve do conteúdo;

- Os alunos e o professor aproveitam a necessidade de distanciamento social para ressignificar o papel de ambos, vislumbrando adotar tendências mais modernas e eficazes no processo de ensino-aprendizagem;

-As TDICs são mais aceitas e incorporadas no âmbito educacional.

Como o Ensino Remoto só pode ser estabelecido por intermédio de utilização das TDICs e de um ambiente virtual de aprendizagem que possibilite a comunicação dos professores e alunos, esta pesquisa utiliza a plataforma PLURALL, sendo esta um ambiente virtual de aprendizagem disponível para as instituições que adotam sistemas de ensino vinculados à SOMOS Educação (grupo brasileiro de Educação Básica).

Ao entrar nessa plataforma, os professores encontram uma série de ferramentas para auxiliar no desenvolvimento das metodologias de ensino-aprendizagem, conforme ilustra a Figura 4. Entre elas destaca-se os Cadernos Digitais. Esse espaço oferece acesso às apostilas ou aos manuais do professor adotados pela instituição, sendo possível editá-los provisoriamente durante a aula, utilizando canetas, marca-textos e caixas de texto, recurso didático extremamente útil ao Ensino Remoto. Algumas melhorias foram implementadas na plataforma em virtude da adoção dessa forma de ensino, como foi o caso da incorporação do Hagouts Meet, ferramenta do Google que viabiliza as aulas ao vivo.

Figura 4 - Estrutura principal da Plataforma PLURALL.

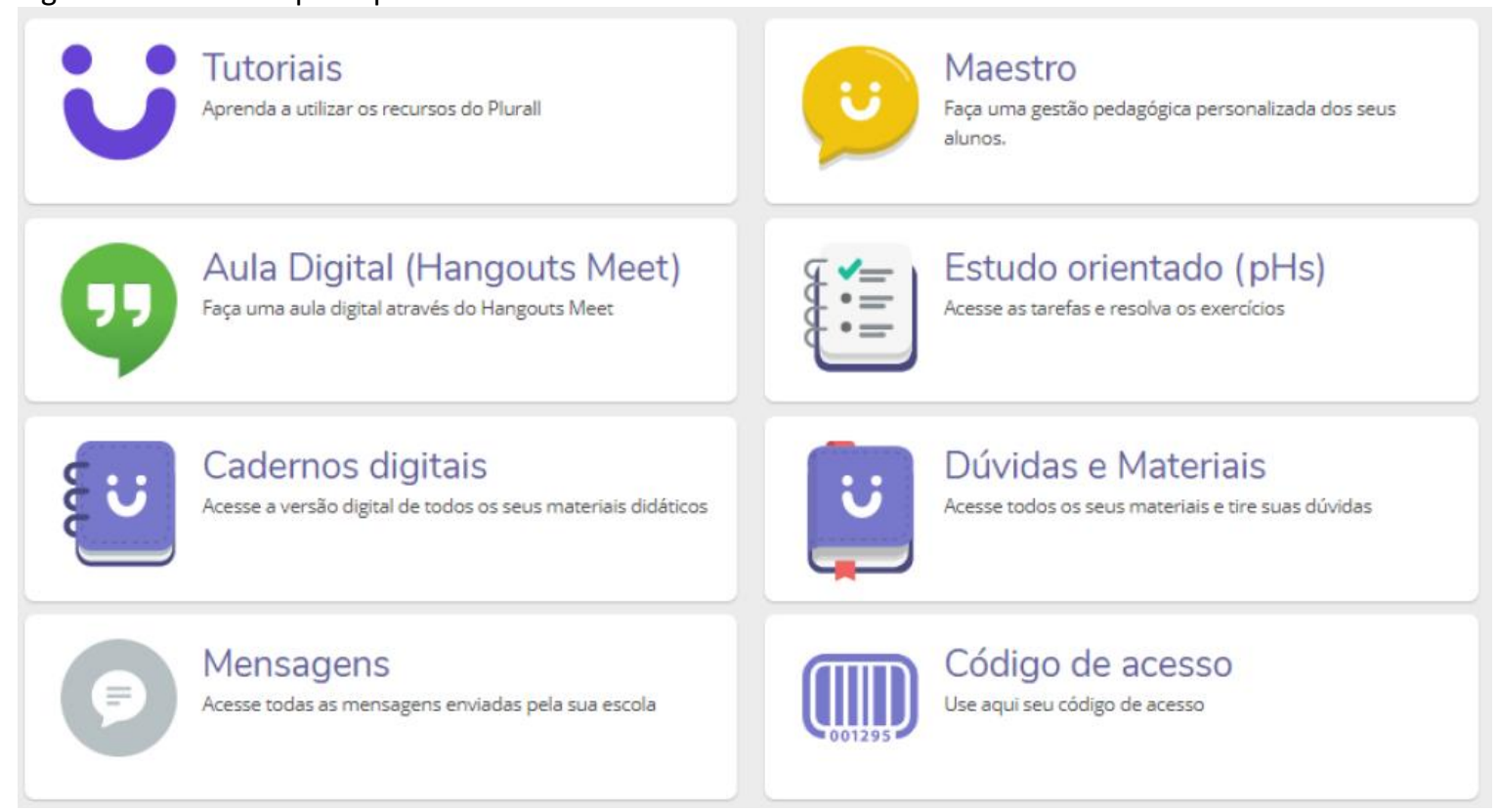

Fonte: Plataforma Plurall ${ }^{3}$ (2020).

${ }^{3}$ Disponível em <https://www.plurall.net/>. Acesso em: 07 de jun. de 2020. 
Ainda na Figura 4, é possível visualizar a aba Maestro, local em que os professores conseguem criar materiais e atividades (sem registro de resposta, objetivas, discursivas e atividades com mais de uma alternativa correta) sendo possível utilizar imagens, vídeos, planilhas e links como ferramentas de ensino. Nessa seção, o professor também consegue enviar os materiais e exercícios preparados para os alunos, configurar a partir de quando os alunos poderão acessar aquele item e, no caso das atividades, definir se o aluno terá prazo para responder e quando o aluno poderá acessar o gabarito; imediatamente após executar a tarefa ou quando o prazo foi expirado. Ainda nessa seção, o professor consegue visualizar tudo que ele já enviou para as turmas, quais alunos visualizaram o material ou responderam a atividade, e, caso a atividade seja objetiva, o professor consegue acessar o percentual de acertos. $O$ docente também poderá acessar um relatório da atividade. Outra utilidade do Maestro é fazer e visualizar o agendamento das aulas ao vivo no Hangouts Meet.

Por fim, a seção Dúvidas e Materiais também permite que o professor acesse o material didático, os Estudos Orientados e Simulados disponíveis pela plataforma, até as provas anteriores do ENEM e as videoaulas previamente disponibilizadas.

Na próxima seção, será apresentada toda a operacionalidade sobre aplicação deste novo modelo de ensino Sala de Aula Invertida adaptada ao Ensino Remoto.

\section{Procedimentos Metodológicos e Contexto da Pesquisa}

Esta seção contém a descrição da metodologia utilizada na presente pesquisa, apresentando a metodologia de pesquisa adotada, os sujeitos envolvidos na experimentação, as etapas desenvolvidas para a construção deste trabalho, a Sequência Didática proposta, as ferramentas utilizadas para alcançar os objetivos estipulados e os instrumentos empregados para coletar os dados que foram posteriormente avaliados.

Em relação à natureza, pode-se afirmar que esta pesquisa é aplicada, visto que ela traz resultados a respeito da implementação da estratégia de ensino Sala de Aula Invertida adaptada, experimentada em um conteúdo específico da Matemática, a Análise Combinatória. Segundo Gil (2008, p.27), a pesquisa aplicada "tem como característica fundamental o interesse na aplicação, utilização e consequências práticas dos conhecimentos".

Ao propor a utilização de uma metodologia de ensino para aprimorar o processo de aprendizagem, esta pesquisa se classifica como exploratória em relação aos seus objetivos, dado que ela "têm como principal finalidade desenvolver, esclarecer e modificar conceitos e ideias, tendo em vista a formulação de problemas mais precisos ou hipóteses pesquisáveis para estudos posteriores" (GIL, 2008, p.27).

Além disso, quanto aos procedimentos, esta pesquisa é classificada como intervenção pedagógica, já que "à intenção é descrever detalhadamente os procedimentos realizados, avaliando-os e produzindo explicações plausíveis, sobre seus efeitos, fundamentadas nos dados e em teorias pertinentes" (DAMIANI, et al., 2013, p.59).

O instrumento de pesquisa foi constituído por: autorização da escola para a realização da experimentação da pesquisa; autorização dos responsáveis para a participação dos alunos; testes de verificação de aprendizagem; descrição da atividade lúdica coletiva; modelo de questionário aplicado. A coleta de dados foi feita por meio da observação durante o desenvolvimento das atividades propostas e da aplicação do questionário. Todos estes instrumentos podem ser vistos em detalhes em (Marques, 2020g). 
A presente pesquisa foi experimentada na Escola Positiva, instituição privada de ensino localizada na cidade de Barra de São João, segundo distrito do município de Casimiro de Abreu, no Estado do Rio de Janeiro. O conteúdo de Análise Combinatória está presente no currículo comum da 2 a série do Ensino Médio e, portanto, a turma escolhida para experimentação das atividades foi esta, onde 16 (dezesseis) alunos devidamente matriculados participaram da experimentação.

\subsection{As Etapas da Pesquisa}

Para investigar os efeitos do Ensino Híbrido no processo de ensino-aprendizagem da Análise Combinatória utilizando a metodologia da Sala de Aula Invertida adaptada ao Ensino Remoto para os alunos da 2a série do Ensino Médio, a presente pesquisa foi dividida em oito etapas, a saber: 1 - Fazer levantamento bibliográfico sobre a história e a teoria da Análise Combinatória, sobre as dificuldades no processo de ensino-aprendizagem desse assunto e sobre a presença desse conteúdo nos Documentos Oficiais; 2 - Fazer revisão bibliográfica sobre o acesso às TDICs no Brasil, sobre a presença das TDICs na Educação, sobre as Metodologias Ativas e o Ensino Híbrido, dando ênfase na metodologia Sala de Aula Invertida. Posteriormente, reunir informações a respeito do Ensino Remoto no Brasil durante a pandemia causada pelo novo coronavírus e adaptar a metodologia adotada a esse contexto; 3 - Elaborar uma Sequência Didática para experimentação da pesquisa; 4 - Gravar e editar as videoaulas sobre Análise Combinatória para os estudantes do Ensino Médio; 5 - Pesquisar e selecionar questões do conteúdo de Análise Combinatória para compor as atividades de verificação de aprendizagem; 6 - Pesquisar e selecionar uma atividade lúdica a respeito do conteúdo de Análise Combinatória para os alunos desenvolverem, com objetivo de proporcionar um ambiente de aprendizagem descontraído; 7 - Elaborar o questionário para coleta de dados; 8 - Experimentar a metodologia proposta; 9 - Organizar os resultados obtidos para as análises qualitativa e quantitativa; 10 - Analisar e discutir os resultados obtidos com os instrumentos de coletas de dados.

\subsection{A Sequência Didática}

Adiante é apresentado os tópicos da Sequência Didática elaborada para experimentação desta pesquisa.

-Tema: Análise Combinatória.

- Conteúdos pré-requisitos: Fatorial de um número natural e Princípio Fundamental da Contagem.

- Conteúdos abordados: Permutação Simples, Arranjo Simples, Combinação Simples, Permutação com Repetição e Permutação Circular.

- Tempo de execução: 35 aulas (uma aula equivalente a 50 minutos).

- Materiais necessários: Para desenvolvimento dessa Sequência Didática de forma remota, tornou-se necessário a utilização de Internet e de um ambiente virtual de aprendizagem. Nesta pesquisa foi utilizado a Plataforma PLURALL e um dispositivo eletrônico para acesso; mais detalhes na próxima seção.

- Metodologia de ensino: Ensino Híbrido - Sala de Aula Invertida Adaptada ao Ensino Remoto.

Visando aplicar a metodologia da Sala de Aula Invertida durante o desenvolvimento do

Ensino Remoto, o processo de ensino-aprendizagem do conteúdo aconteceu em dois momentos, a saber: 1 - Assíncrono: disponibilização da videoaula com o conteúdo na 
plataforma e seleção de exercícios de fixação da apostila, que foram entregues para os pesquisados via e-mail, para garantir que os alunos acompanhassem o sistema de Ensino Remoto e para possibilitar o surgimento de dúvidas, que seriam posteriormente esclarecidos pelos pesquisadores; 2 - Síncrono: aulas ao vivo com os pesquisadores utilizando o Hangouts Meet do Google - já incorporado à plataforma PLURALL, para revisar o conteúdo estudado e esclarecer as dúvidas encontradas pelos alunos. Essas aulas foram posteriormente disponibilizadas na plataforma PLURALL para que os alunos que não puderam comparecer tivessem a oportunidade de assistir.

- Objetivos: Promover o ensino da Análise Combinatória e suas técnicas de contagem, possibilitando aplicações em situações cotidianas por meio da análise qualitativa.

- Instrumentos Avaliativos: Ao longo do desenvolvimento do conteúdo, foram aplicadas três Atividades Diagnósticas (AD1, AD2 e AD3) com objetivo de visualizar quais parcelas do conteúdo ainda não estavam claras para os alunos e possibilitar a elucidação dessas dificuldades, além de estabelecer estatisticamente o desempenho desses alunos; essas atividades eram majoritariamente objetivas e foram desenvolvidas na plataforma PLURALL e no Google Forms. Ao final da Sequência Didática, os alunos desenvolveram uma Atividade Lúdica (AL) em dupla e fizeram individualmente duas atividades avaliativas na plataforma PLURALL, denominadas Atividade de Verificação de Aprendizagem (AVA) e Avaliação Somativa (AS).

O cronograma do desenvolvimento das aulas está disposto no Quadro 1.

Quadro 1 - Cronograma do desenvolvimento da Sequência Didática.

\begin{tabular}{|c|c|c|}
\hline $\begin{array}{c}\text { Data } \\
\text { (Tempo-hora/aula) }\end{array}$ & Metodologia & Conteúdo e Atividades \\
\hline $13 / 03 / 2020$ (1h/a) & Apresentação & Ensino Híbrido - Sala de Aula Invertida \\
\hline $27 / 03 / 2020$ (3h/a) & Assíncrona & Permutação - Disponibilização dos Vídeos 1, 2, 3 e AD1 \\
\hline 03/04/2020 (3h/a) & Síncrona & $\begin{array}{l}\text { Permutação e Arranjo - Aula Remota para correção da } \\
\text { AD1; } \\
\text { Disponibilização do Vídeo 4; Seleção de exercícios }\end{array}$ \\
\hline 08/04/2020 (3h/a) & $\begin{array}{l}\text { Síncrona e } \\
\text { Assíncrona }\end{array}$ & $\begin{array}{c}\text { Arranjo e Combinação - Aula Remota para preleção das } \\
\text { dúvidas; Disponibilização do Vídeo 5; Seleção de } \\
\text { exercícios }\end{array}$ \\
\hline $17 / 04 / 2020(3 \mathrm{~h} / \mathrm{a})$ & Síncrona & Combinação - Aula Remota para preleção das dúvidas \\
\hline 24/04/2020 (3h/a) & Síncrona & $\begin{array}{c}\text { Permutação, Arranjo e Combinação - Aula Remota para } \\
\text { preleção das dúvidas; Revisão do Conteúdo }\end{array}$ \\
\hline 08/05/2020 (3h/a) & $\begin{array}{l}\text { Síncrona e } \\
\text { Assíncrona }\end{array}$ & $\begin{array}{l}\text { Permutação, Arranjo e Combinação - Disponibilização da } \\
\text { AD2; Aula remota para correção da AD2 }\end{array}$ \\
\hline $15 / 05 / 2020(3 \mathrm{~h} / \mathrm{a})$ & $\begin{array}{l}\text { Síncrona e } \\
\text { Assíncrona }\end{array}$ & $\begin{array}{l}\text { Permutação, Arranjo e Combinação - Disponibilização da } \\
\text { AD3; Aula remota para correção da AD3 }\end{array}$ \\
\hline $22 / 05 / 2020(3 \mathrm{~h} / \mathrm{a})$ & Assíncrona & $\begin{array}{c}\text { Permutação Cíclica, Permutação com Elementos } \\
\text { Repetidos - Disponibilização do Vídeo 6; Seleção de } \\
\text { exercícios }\end{array}$ \\
\hline 29/05/2020 (3h/a) & $\begin{array}{l}\text { Síncrona e } \\
\text { Assíncrona }\end{array}$ & $\begin{array}{l}\text { Permutação Cíclica, Permutação com Elementos } \\
\text { Repetidos e Análise Combinatória - Aula Remota para } \\
\text { preleção das dúvidas; Seleção de exercícios }\end{array}$ \\
\hline 05/06/2020 (3h/a) & Síncrona & $\begin{array}{c}\text { Análise Combinatória - Aula Remota para preleção das } \\
\text { dúvidas; Revisão do Conteúdo; Disponilização e } \\
\text { Explicação da AL }\end{array}$ \\
\hline $12 / 06 / 2020(1,5 h / a)$ & Assíncrona & Análise Combinatória - AVA \\
\hline
\end{tabular}




\begin{tabular}{|c|c|c|}
\hline $19 / 06 / 2020(1,5 \mathrm{~h} / \mathrm{a})$ & Síncrona & Análise Combinatória - AVA \\
\hline $26 / 06 / 2020(1,5 \mathrm{~h} / \mathrm{a})$ & Assíncrona & Análise Combinatória - AVA \\
\hline $03 / 07 / 2020(2 \mathrm{~h} / \mathrm{a})$ & $\begin{array}{c}\text { Síncrona e } \\
\text { Assíncrona }\end{array}$ & $\begin{array}{c}\text { Correção da Avaliação Somativa - Disponibilização do } \\
\text { Questionário discente }\end{array}$ \\
\hline
\end{tabular}

Fonte: Elaborado pelos autores, 2020.

\subsection{A Elaboração das Videoaulas, da Atividades Lúdica e das Atividades Avaliativas}

Com intuito de garantir a qualidade do conteúdo ministrado aos estudantes, foram elaboradas nesta pesquisa videoaulas para serem utilizadas na metodologia da Sala de Aula Invertida adaptada ao Ensino Remoto. Foram criadas, ao todo, seis videoaulas sobre o conteúdo de Análise Combinatória, que foi segmentado de acordo com o que está disposto no Quadro 2.

Quadro 2 - Descrições das Videoaulas.

\begin{tabular}{|c|c|c|}
\hline \multicolumn{1}{|c|}{ Vídeos } & Conteúdo & $\begin{array}{c}\text { Duração } \\
\text { (Horas) }\end{array}$ \\
\hline Vídeo 1 (Marques, 2020a) & Permutação Simples & $00: 03: 11$ \\
\hline Vídeo 2 (Marques, 2020b) & Permutação Simples com Restrições & $00: 21: 21$ \\
\hline Vídeo 3 (Marques, 2020c) & Permutação Simples e Anagramas & $00: 05: 20$ \\
\hline Vídeo 4 (Marques, 2020d) & Arranjo Simples & $00: 03: 55$ \\
\hline Vídeo 5 (Marques, 2020e) & Combinação Simples & $00: 05: 17$ \\
\hline Vídeo 6 (Marques, 2020f) & Permutação Circular e Permutação com Elementos & $00: 04: 34$ \\
\hline
\end{tabular}

Fonte: Elaborado pelos autores, 2020.

As videoaulas são curtas e descontraídas com o propósito de tornar o processo de ensino-aprendizagem mais fluido e interessante. Para isso, foi utilizado o programa Adobe Spark Video, que é uma ferramenta de design on-line, que permite a elaboração de imagens para redes sociais, de páginas da Web e de vídeos curtos, utilidade relevante para esta pesquisa.

Nesse sentido, o programa Adobe Spark Video foi escolhido por oferecer uma interface simples de usar que permite a elaboração de vídeos sem que o autor apareça, por ter modelos prontos que facilitam o processo de criação e por permitir introduzir música ao fundo do vídeo, tornando a videoaula mais divertida. A cada apresentação criada, o autor tem opção de selecionar um layout dentre os modelos oferecidos, escolher um tema (cores e fonte do texto), definir o formato retangular ou quadrado, além de escolher e configurar a música de fundo (Figura 5). Outrossim, o autor também tem a opção de adicionar a cada slide textos, ícones, imagens e vídeos, utilizando o banco de dados disponível ou fazendo upload do arquivo, e também gravar um áudio explicando o conteúdo exposto. Ao final do projeto, o programa transforma toda a criação em um vídeo que fica disponível para download.

Sendo assim, buscando alcançar o efetivo entendimento do conteúdo estudado pelos alunos, todas as videoaulas utilizadas nesta pesquisa foram gravadas de acordo com a sequência a seguir: 1 - Exposição de uma situação cotidiana em que os alunos visualizassem a necessidade de aplicação do conteúdo; 2 - Solução dessa situação utilizando o Princípio Fundamental da Contagem; 3 - Apresentação do conceito e da fórmula utilizada em cada caso; 4 - Demonstração de outra aplicação do conteúdo, agora utilizando a fórmula apresentada; 5 - Indagação de como o aluno resolveria um desafio envolvendo o conceito estudado.

Além dos alunos receberem as videoaulas nos momentos assíncronos, eles também receberam uma seleção de exercícios com objetivo de praticar os conceitos apresentados e 
identificar as lacunas de aprendizagem, permitindo que, nas aulas síncronas, as dificuldades encontradas no processo da construção do saber fossem esclarecidas. Para isso, os alunos também praticaram algumas atividades durante as aulas ao vivo, as chamadas Atividades Diagnósticas. Elas foram criadas ou selecionadas com o objetivo de verificar o nível de entendimento dos alunos em relação ao conteúdo e de estabelecer uma revisão dos conceitos apresentados.

Figura 5 - Visualização da ferramenta Spark Adobe Video.

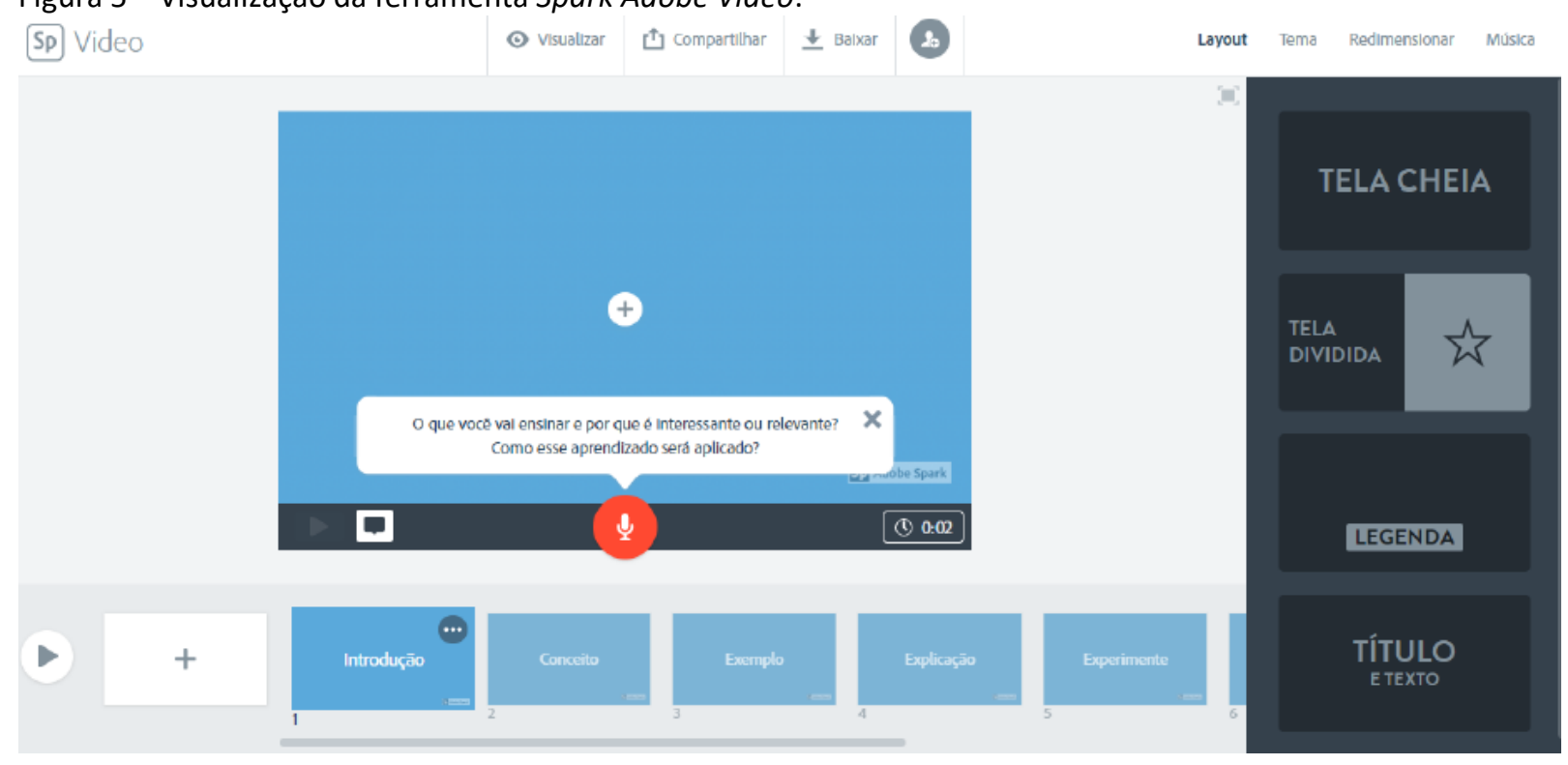

Fonte: Spark Adobe Video ${ }^{4}$ (2020).

Outra estratégia adotada nesta pesquisa além das Atividades Diagnósticas, foi a aplicação de uma Atividade Lúdica. Segundo Modesto e Rubio (2014, p.14), "Sabe-se que para estimular o sujeito e promover seu desenvolvimento é preciso propor atividades desafiadoras, significativas, que desperte o interesse, e as atividades lúdicas podem ser uma excelente ferramenta pedagógica e psicopedagógica". Para escolher a Atividade Lúdica, foi considerado o contexto do Ensino Remoto, em que a presença dos estudantes em um único espaço físico não seria possível. Após uma ampla pesquisa, decidiu-se pelo Jogo Senha (Ambrozi, 2018). A escolha desse jogo foi feita por abordar principalmente o Princípio Multiplicativo, que é à base da construção da Análise Combinatória e pela possibilidade dele ser desenvolvido em dupla de forma remota. Depois de jogar, cada dupla elaborou um relatório com o resultado obtido e também com as respostas de algumas questões propostas pelos pesquisadores, com objetivo de estimular o entendimento da influência das possíveis variações do jogo no resultado, sob a ótica da Análise Combinatória.

Uma vez desenvolvido todo conteúdo de Análise Combinatória, inclusive a parte de Permutações com Elementos Repetidos e Permutações Circulares, e todas as atividades citadas anteriormente, os alunos fizeram o Teste de Verificação de Aprendizagem, com objetivo de reconhecer as lacunas de aprendizagem e de promover uma intervenção para fornecer o conhecimento ainda não compreendido.

Por fim, a última atividade desenvolvida foi a Avaliação Somativa com o mesmo formato do Teste de Verificação de Aprendizagem. Essas atividades foram elaboradas visando

${ }^{4}$ Disponível em <https://spark.adobe.com/pt-BR/>. Acesso em: 07 de jun. de 2020. 
a aproximação do conteúdo de Análise Combinatória em situações cotidianas, concluindo o processo de avaliação proposto nesta pesquisa. A construção do Questionário foi feita de forma que ele pudesse cumprir o objetivo de permitir que os alunos avaliassem a metodologia de ensino experimentada. Detalhes específicos destas atividades serão discutidos na próxima seção.

Vale ressaltar que as questões do Teste de Verificação de Aprendizagem e as questões da Avaliação Somativa são inéditas e podem ser vistas na íntegra em (Marques, 2020g).

\section{Resultados}

Neste artigo será feita uma breve descrição sobre a experimentação da Sequência Didática, com abordagens quantitativas e qualitativas, com destaque para as percepções dos estudantes, as intervenções pedagógicas e algumas conclusões. Devido à dimensão deste artigo, serão apresentadas análises sucintas das Atividades Diagnósticas, Atividade Lúdica, AVA, Avaliação Somativa e Questionário.

A Atividade Diagnóstica 1 (AD1) teve como objetivo possibilitar um contato inicial com a prática do assunto abordado nos vídeos. A Figura 6 mostra os resultados dos quinze alunos que responderam a Atividade Diagnóstica 1. O percentual de acerto médio desses alunos foi cerca de $57 \%$. Até este momento, os alunos haviam compreendido o conceito de permutação mais relacionado a anagramas. Foi constatado nesta Atividade que as questões que envolviam anagramas com restrição de posição foram as questões que eles sentiram maior dificuldade em resolver.

Figura 6-Resultado da Atividade Diagnóstica 1: percentual de acerto por discente.

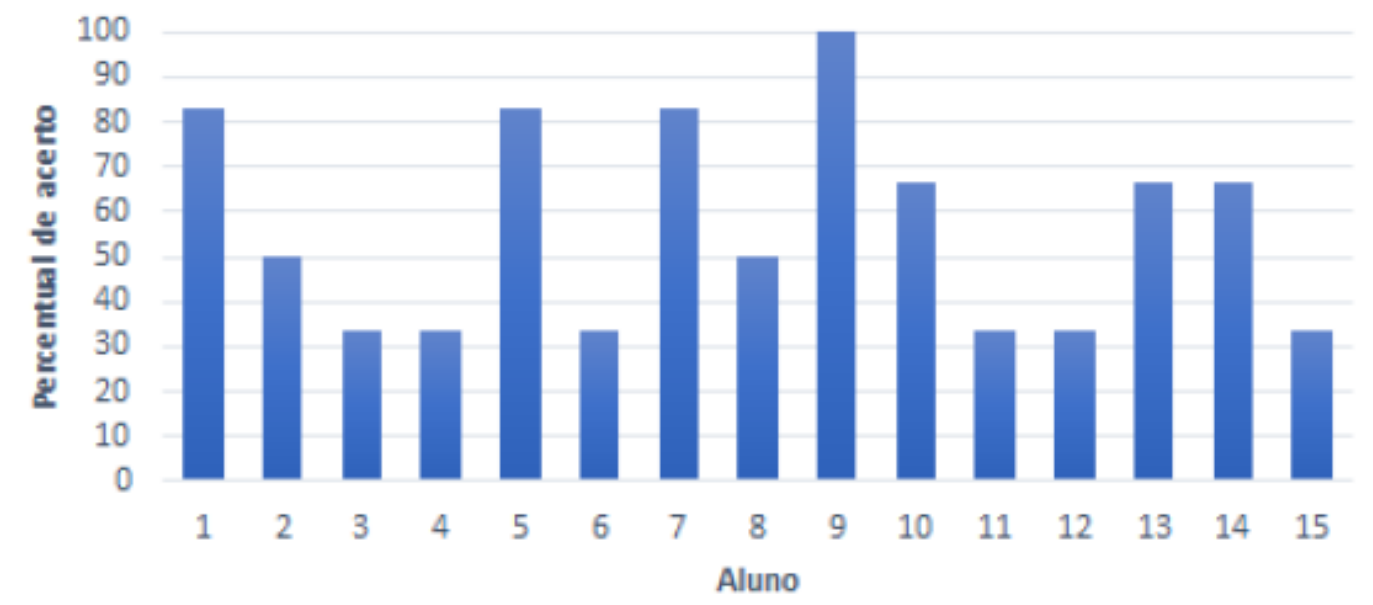

Fonte: Dados da pesquisa, 2020.

Encerrando o prazo de desenvolvimento da AD1, essas questões foram resolvidas pelos pesquisadores juntamente com a turma. É importante destacar que a plataforma PLURALL possui um recurso que permite que o professor visualize o percentual de marcação de cada alternativa de uma determinada questão objetiva de múltipla escolha. Assim, tornase mais fácil identificar qual foi o principal equívoco na construção do raciocínio dos alunos que erraram a questão para intervir didaticamente.

Com o desenvolvimento do conteúdo, foi aplicado a Atividade Diagnóstica 2 (AD2). As três primeiras questões dessa atividade eram abertas e tinham objetivo de verificar se os alunos entenderam os conceitos abordados até o momento. A Questão 1 perguntava " $O$ que 
é fatorial de um número natural?" e onze dos dezesseis alunos (quase 70\%) responderam de forma completa e correta afirmando que "é a multiplicação dele com seus antecessores até o 1 " ou "é o produto de todos os inteiros positivos menores ou iguais a $n$ ". Quatro alunos deram respostas incompletas, fazendo notar que eles conheciam o conceito mas tiveram dificuldade de transcrevê-lo, como mostrado a seguir: "produto dos números", nesse caso, não foi especificado quais números; "é o produto de todos os números anteriores a $n$ "; aqui faltou dizer que o próprio $n$ estava incluso, além dos anteriores, até o 1; "são todos os números iguais ou menores que $n "$ "; nesse caso o estudante não mencionou a palavra produto.

A Atividade Diagnóstica 2 também trazia nove questões objetivas de múltipla escolha, cujos resultados estão disponíveis na Figura 7. As Questões com menor percentual de acerto se tratavam de anagramas com restrições, assunto discutido na Atividade Diagnóstica 1. Entretanto o percentual médio de acerto da turma foi quase $60 \%$ nas questões objetivas e $75 \%$ nas discursivas; considerando todas as atividades a média de acerto foi maior que $63 \%$, mostrando que essa dinâmica de atividades trouxe resultados significativos para a aprendizagem dos alunos.

Figura 7 - Resultado da Atividade Diagnóstica 2: percentual de acerto por discente.

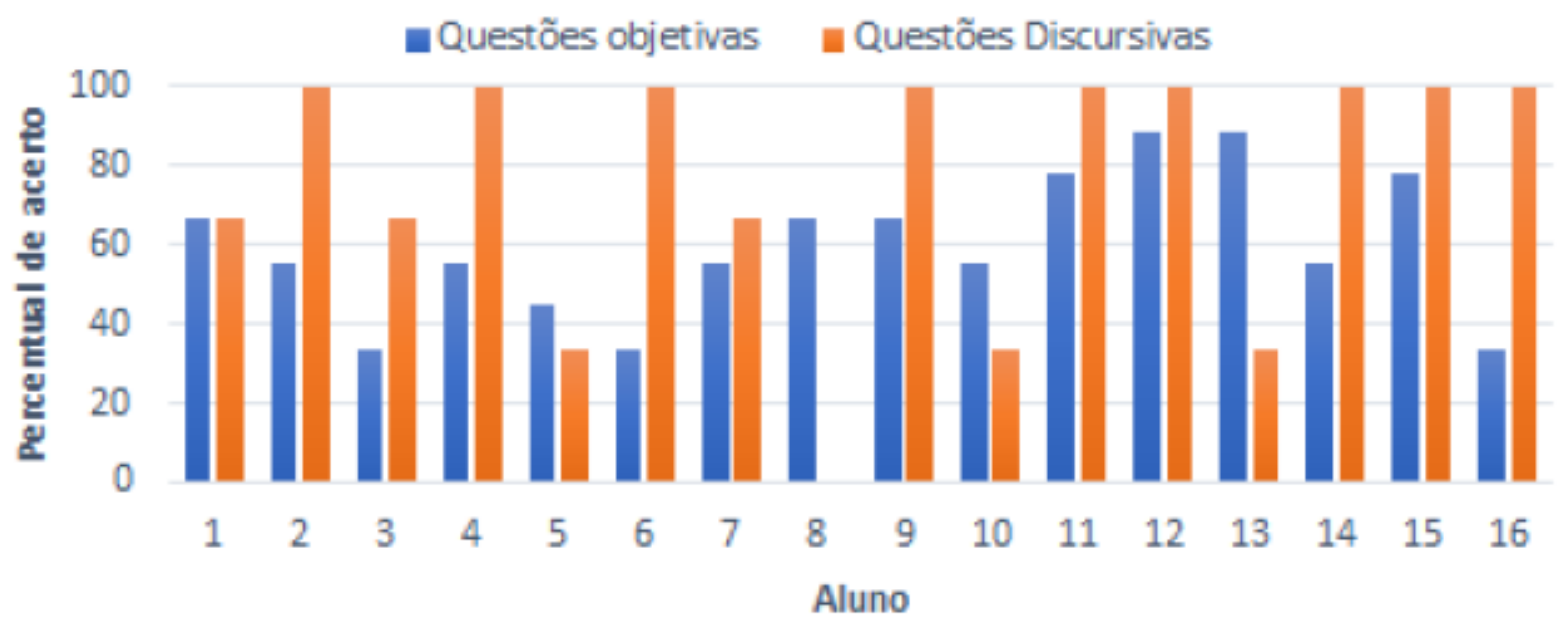

Fonte: Dados da pesquisa, 2020.

$\mathrm{Na}$ aula seguinte à aplicação da AD2, os estudantes fizeram mais uma atividade diagnóstica, a $A D 3$, já que eles demonstraram interesse em praticar um pouco mais o conteúdo. Esta Atividade abordava questões de concurso público, vestibular e questões da OBMEP (Olimpíadas Brasileira de Matemática das Escolas Públicas). A Figura 8 mostra o percentual de acerto por questão nessa atividade. As Questões que tiveram um percentual de acerto menor que $60 \%$ se tratavam do conteúdo de Combinação Simples. Seguindo o mesmo protocolo, os alunos tiveram um encontro ao vivo com os pesquisadores e discutiram todas as questões da atividade, identificando os erros cometidos na construção do raciocínio quantitativo. 
Figura 8-Resultado da Atividade Diagnóstica 3: percentual de acerto por discente.

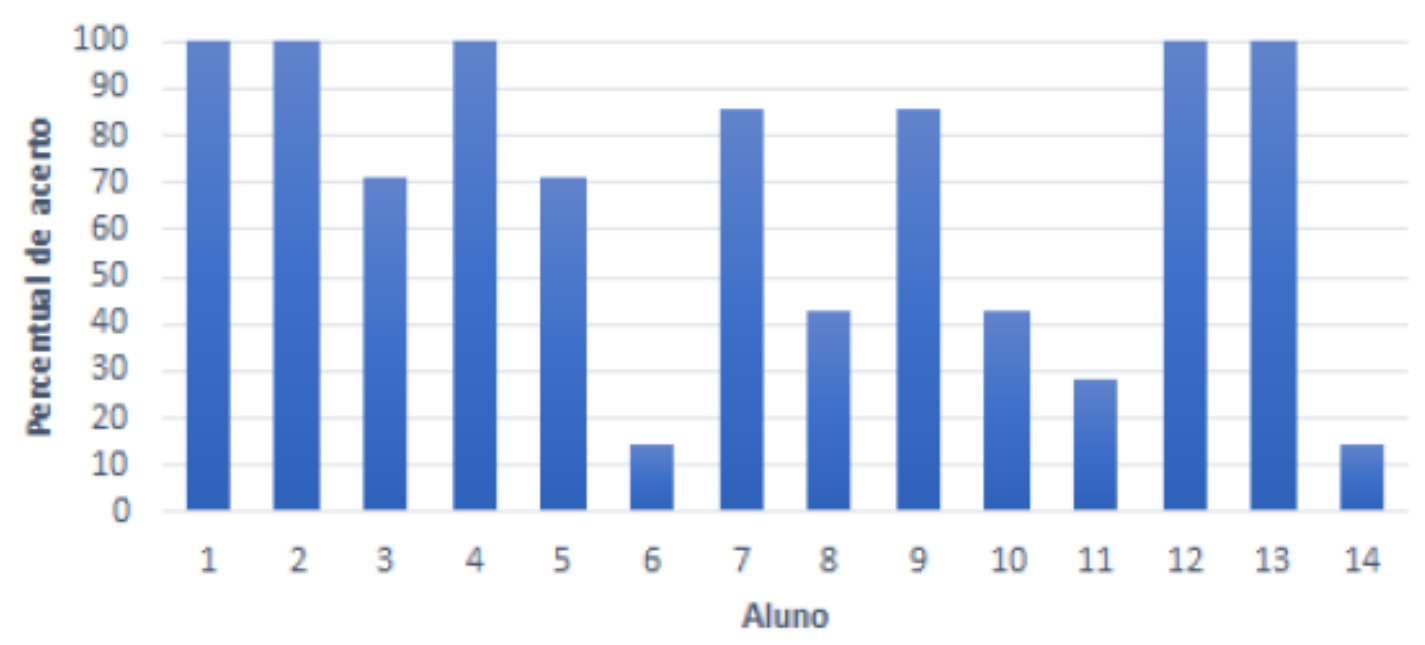

Fonte: Dados da pesquisa, 2020.

Ao final das Atividades Diagnósticas, ocorreu a Atividade Lúdica. Os estudantes receberam o arquivo do Jogo Senha, cujas regras estão disponíveis em (Ambrozi, 2018). Também foi feita uma simulação a respeito do funcionamento do jogo. Eles foram orientados a fazer a troca das cartelas via WhatsApp para facilitar a comunicação e dar fluidez à tarefa. A Figura 9 mostra o resultado da atividade de uma das duplas da turma. De maneira geral, os alunos desenvolveram o jogo corretamente, de maneira que o desafiado seguiu as orientações do desafiador para dar o próximo palpite. No caso desse exemplo, o aluno que foi desafiado na cartela da direita venceu o jogo, uma vez que ele acertou a senha com quatro tentativas, enquanto o seu adversário acertou em cinco tentativas.

Figura 9 - Resultado do Jogo Senha disputada por uma dupla de estudantes.

JOGO SENHA

CARTELA DO DESAFIADO

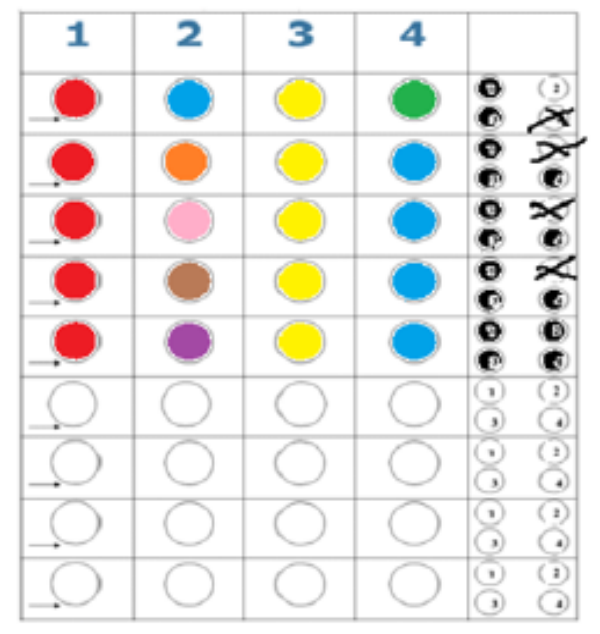

CARTELA DO DESAFIADOR

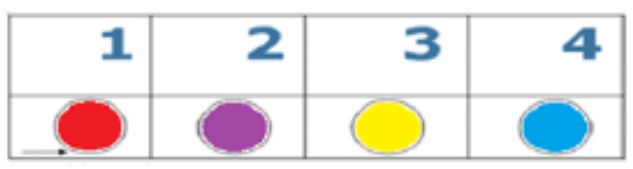

JOGO SENHA

CARTELA Do DESAFIADO

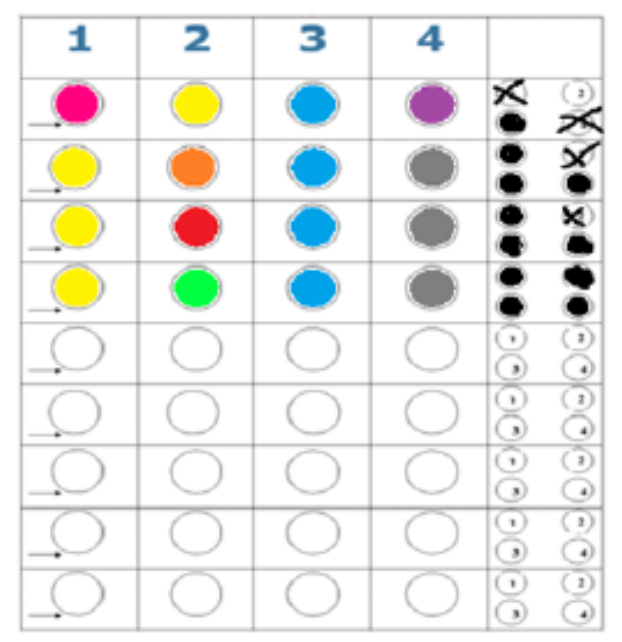

CARTELA DO DESAFIADOR

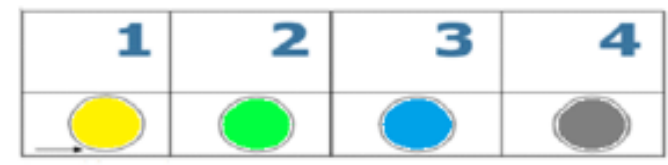

Fonte: Dados da pesquisa, 2020. 
Os alunos também enviaram para os pesquisadores as respostas das perguntas feitas no final da atividade e todos tiveram um bom aproveitamento, com no mínimo $80 \%$ de acerto. É importante destacar que os alunos reconheceram a importância do preenchimento da coluna à direita pelo desafiador, mostrando que essa atitude reduz o número de possibilidades para o desafiado. A última pergunta a ser respondida por cada dupla deu aos alunos a oportunidade de expressar a opinião acerca da atividade. As respostas foram quase sempre positivas, apesar de alguns alunos alegarem que no princípio acharam o jogo complexo. Algumas respostas estão listadas a seguir: "Nós gostamos muito, é uma forma de aprender a matéria jogando."; "Achamos o jogo muito legal, é um jogo que serve não somente para dentro de sala, mas também entre amigos e familiares, muito bom!!!"

A Atividade de Verificação de Aprendizagem (AVA) foi realizada pelos alunos na Plataforma PLURALL. Eles tiveram o prazo de noventa (90) minutos para realizar a atividade que possuía oito questões: quatro objetivas e quatro discursivas. As quatro primeiras questões eram fechadas e tinham como objetivo avaliar a capacidade dos alunos interpretarem pequenas variações de um mesmo problema, trazendo a ideia de Permutação Simples, Princípio Fundamental da Contagem, Permutação com Elementos Repetidos e também a ideia de unir elementos em blocos. De acordo com a Figura 10, dessas questões, os alunos tiveram um bom desempenho apenas na Questão 3, que tratava de Permutação com Elementos Repetidos. A partir da Questão 5, as questões eram abertas e traziam os conceitos de Permutação Simples com anagramas, Permutação Circular, Combinação Simples, Arranjo Simples e Princípio Fundamental da Contagem, trabalhando restrição de posição.

Figura 10 - Resultado da AVA por discente.

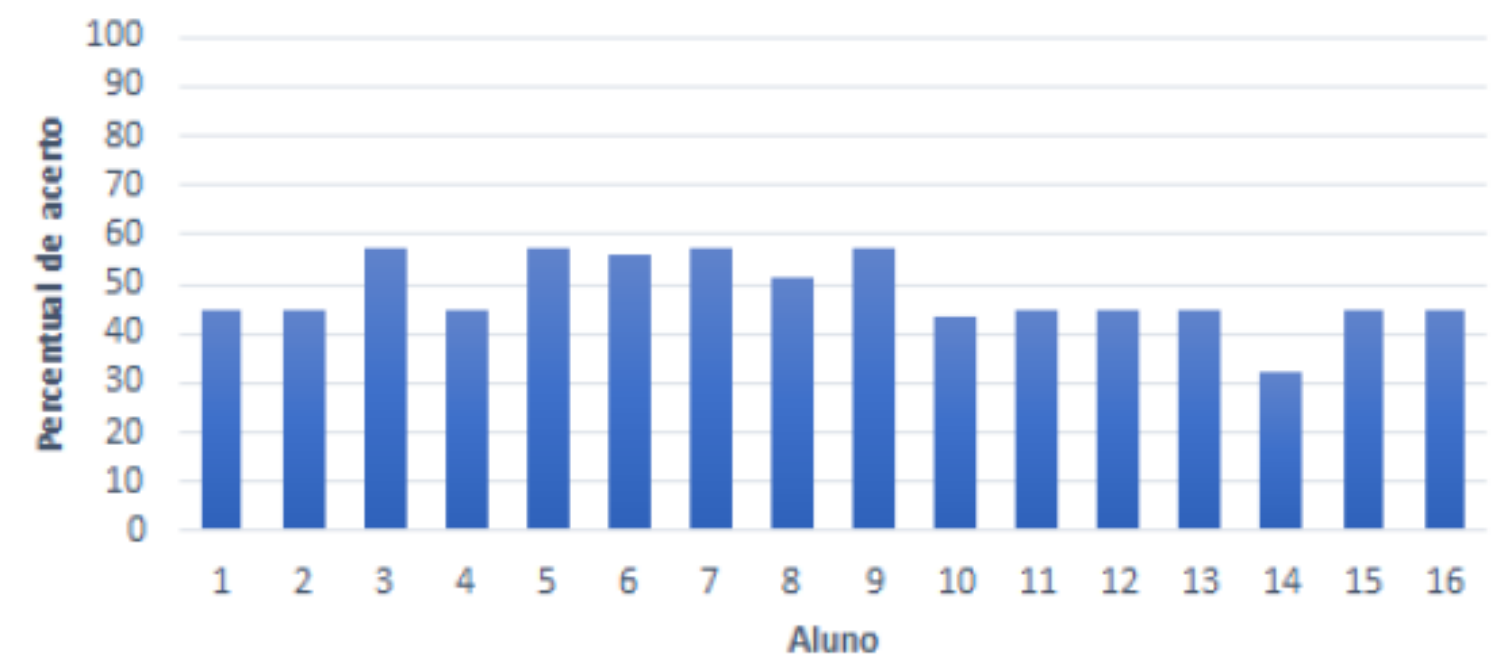

Fonte: Dados da pesquisa, 2020.

A Avaliação Somativa é a última avaliação da experimentação, abordando todo conteúdo de Análise Combinatória com questões inéditas inspiradas na OBMEP. A Figura 11 traz os resultados obtidos nessa avaliação por aluno; o desempenho médio foi $71 \%$ de acerto. As Questões com baixo percentual de acerto tratavam-se de situações em que a solução estava relacionada à Combinação Simples, gerando uma interpretação equivocada de alguns estudantes, os quais abordaram essas questões como Arranjo Simples; outra dificuldade apontada nesta avaliação foi às questões que abordavam Permutação em blocos. Entretanto, 
parte considerável dos estudantes teve um desempenho satisfatório no geral, apresentando uma evolução consistente no decorrer da experimentação.

Este tipo de avaliação é imprescindível para gerar uma autorreflexão dos estudantes para os erros cometidos.

Em relação ao questionário realizado pelos estudantes, este artigo traz os resultados das armações mais relacionados à metodologia Sala de Aula Invertida Adaptada ao Ensino Remoto, com resultados muito satisfatórios em todos os quesitos, como apresenta a Figura 12.

Figura 11 - Resultado da Avaliação Somativa por discente.

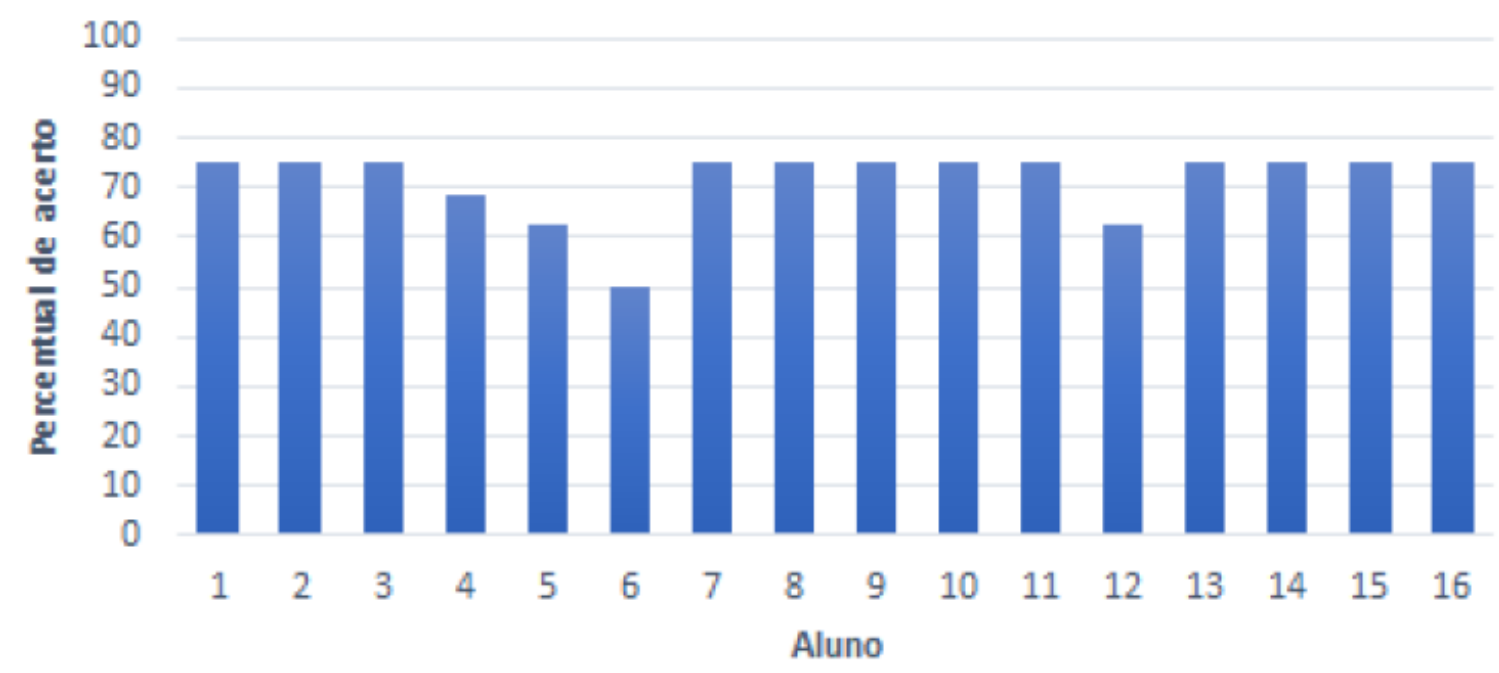

Fonte: Dados da pesquisa, 2020.

Figura 12 - Resultados importantes sobre o relato dos estudantes em relação a metodologia aplicada.

Eu consegui assistir as videoaulas de conteúdo antes da aula online com a professora.

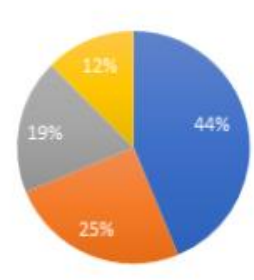

Para desenvolver a

aprendizagem do conteúdo, o modelo da Sala de Aula Invertida se mostrou mais interessante do que o modelo tradicional

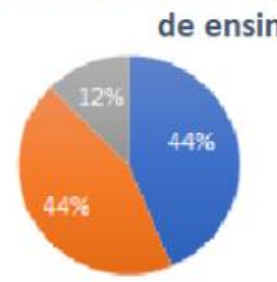

Fonte: Dados da pesquisa, 2020.

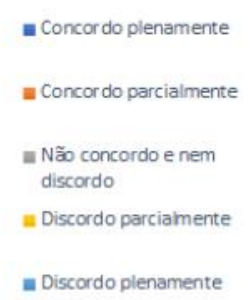

- Discordo plenamente

Boletim online de Educação Matemática, Florianópolis, v. 9, n. 18, p. 122-142, outubro/2021.
Eu julgo como produtivo encontrar a professora na aula síncrona conhecendo o conteúdo que será desenvolvido em sua aula.
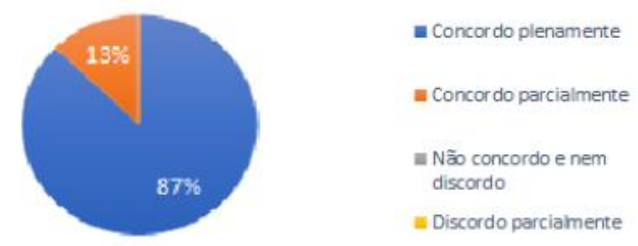

Considero que as videoaulas $e$ as atividades realizadas nas aulas ao vivo contribuíram para o processo de ensino e aprendizagem do tema em estudo.

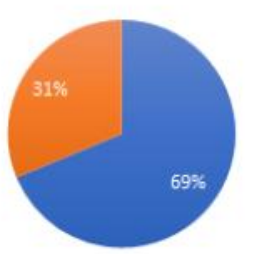

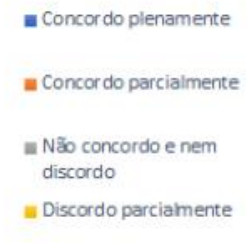

w Concor do plenamente

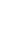


Por fim, os alunos puderam elencar os pontos positivos e negativos da metodologia experimentada. Eles destacaram principalmente: a facilidade de poder ter acesso às videoaulas a qualquer momento e poder explorar os recursos dos vídeos; o fato dos estudantes chegarem à sala de aula virtual com noção do que seria estudado, facilitou na identificação das dúvidas e possibilitou mais tempo para a resolução de exercícios; a dinamização do Ensino Remoto que muitas vezes torna-se cansativo. A seguir uma resposta positiva de um estudante: "Facilitou muito o aprendizado o fato de ter vídeos antes das aulas; consegui entender a matéria em si muito melhor; gostei da forma que os vídeos foram feitos, curtos porém muito detalhado". As principais desvantagens da metodologia apontada por eles estão na dificuldade em assistir à videoaula antes da aula síncrona - por desinteresse ou por excesso de atividades e a dificuldade de ter atenção na aula síncrona, já que nessas aulas o conteúdo é trabalhado por meio dos exercícios. A seguir uma resposta negativa de um estudante sobre a metodologia proposta: "Acho que os pontos negativos estão mais relacionados aos alunos. $O$ aluno pode ter preguiça de assistir os vídeos as vezes. $O$ ruim de tudo é deixar acumular. Fora isso não acho que tenha outro".

A análise dos dados levantados, das justificativas, intervenções pedagógicas e principalmente dos registros das Atividades remotas, permitiram confirmar as vantagens da metodologia da pesquisa proposta. Além disso, foi possível constatar que a Sequência Didática totalmente integrada com a tecnologia contribui para a construção do conhecimento em Análise Combinatória.

\section{Considerações finais}

Analisando as respostas obtidas em todas as questões do Questionário e também os resultados obtidos nas avaliações desenvolvidas com os estudantes, pode-se afirmar que a metodologia de ensino Sala de Aula Invertida Adaptada ao Ensino Remoto se mostrou eficaz para o aprendizado da Análise Combinatória durante a pandemia, e as vantagens dessa estratégia se tornaram mais evidentes nessa experimentação do que as desvantagens.

No que diz respeito ao Ensino Remoto, pode-se dizer que ele se mostrou como uma boa alternativa para garantir a continuidade do ano letivo e para minimizar as perdas educacionais acarretadas pela necessidade de isolamento social. No entanto, existem fatores que podem afetar negativamente esta modalidade de ensino, como: perda de conexão, falta de energia elétrica, atualização do computador no momento da aula, ruídos em torno do estudante ou professor que está utilizando o microfone, entre outros. Todavia com bom senso e paciência sempre é possível encontrar uma saída para contornar um possível problema. Também é importante salientar que existem vantagens na implementação do Ensino Remoto, destacando a facilidade de pesquisa na internet e utilização de mídias educacionais como imagens, softwares, vídeos, simuladores, entre outras.

Ainda nesta pesquisa, foi possível constatar a importância do papel do professor como intermediador do processo de construção do saber bem como do desenvolvimento de atividades distintas para avaliar o nível de compreensão do conteúdo e identificar as lacunas do conhecimento.

Em síntese, espera-se que esta pesquisa sirva de suporte didático-pedagógico para os professores de matemática que desejam ter uma práxis inovadora, principalmente neste período de isolamento social, contribuindo com a promoção do cenário atual da educação brasileira. 


\section{Referências}

AMBROZI, Luiz. Jogos em uma sequência didática para o ensino de análise combinatória. $162 f$. 2018. Dissertação (Mestrado). Universidade de Caxias do Sul, Caxias do Sul, 2018.

ARANHA Franciso; FEFERBAUM Marina. Ensino Inovativo. Revista Ei! Ensino Inovativo.Volume Especial, 2015.

BERGMANN, Jonathan; SAMS, Aaron. Sala de aula invertida: uma metodologia ativa de aprendizagem. Rio de Janeiro: LTC, 2016.

BRASIL. Nota de esclarecimento do CNE. MEC. Portal do CONSED - Conselho Nacional de Secretários de Educação, Brasília, DF, 2020. Disponível em:

http://consed.org.br/media/download/5e78b3190caee.pdf. Acesso em: 08 set. 2020.

BRASIL. Parecer CNE/CP no 5/2020. Portal do MEC, Brasília, DF, 2020. Disponível em:

http://portal.mec.gov.br/index.php?option=com_docman\&view=download\&alias= 145011-pcp00520\&category_slug=marco-2020-pdf\&Itemid=30192. Acesso em: 08 set. 2020.

CHRISTENSEN, Clayton; HORN, Michael; STAKER, Heather. Ensino híbrido: uma inovação disruptiva? uma introdução à teoria dos híbridos. Clayton Christensen Institute for disruptive innovation, 2013.

DAMIANI, Magda Floriana; ROCHEFORT, Renato Siqueira; CASTRO, Rafael Fonseca; DARIZ, Marion Rodriguea; PINHEIRO, Silva Siqueira. Discutindo pesquisas do tipo intervenção pedagógica. Cadernos de educação, n. 45, p. 57-67, 2013.

GIL, Antônio Carlos. Métodos e técnicas de pesquisa social. 6ạ. ed. São Paulo, SP: Editora Atlas SA, 2008.

MARQUES, Brunna Seadi Lima. Vídeo 1: Permutação simples, 2020. Disponível em: https://www.youtube.com/watch?v=Há OJOvRJ48\&feature=youtu.bej. Acesso em: 23 de novembro de 2020a.

MARQUES, Brunna Seadi Lima. Vídeo 2: Permutação simples com restrições, 2020. Disponível em: https://www.youtube.com/watch?v=DCJLNhPPEro\&feature=youtu.bej. Acesso em: 23 de novembro de $2020 \mathrm{~b}$.

MARQUES, Brunna Seadi Lima. Vídeo 3: Permutação Simples com Anagramas, 2020. Disponível em: https://www.youtube.com/watch?v=CD5SrM8rZdE\&feature=youtu.bej. Acesso em: 23 de novembro de 2020 c.

MARQUES, Brunna Seadi Lima. Vídeo 4: Arranjo Simples, 2020. Disponível em: https://www.youtube.com/watch?v=nV5a9ZwESQo\&feature=youtu.bej. Acesso em: 23 de novembro de $2020 d$.

MARQUES, Brunna Seadi Lima. Vídeo 5: Combinação Simples, 2020. Disponível em: https://www.youtube.com/watch?v=2sj UYhDnE\&feature=youtu.bej. Acesso em: 23 nov. 2020e.

MARQUES, Brunna Seadi Lima. Vídeo 6: Permutação Cíclica, 2020. Disponível em: https://www.youtube.com/watch?v=|8ZvThcdxbU\&feature=youtu.bej. Acesso em: 23 nov. $2020 f$. 
MARQUES, Brunna Seadi Lima. Instrumento de Pesquisa, 2020. Disponível em:

https://drive.google.com/drive/folders/1EA6-P On6qx9xpnBCEtxyePaKbrl5hgt?usp=sharingi. Acesso em: 23 nov. $2020 \mathrm{~g}$.

MODESTO, Mônica Cristina; RUBIO, Juliana de Alcântara Silveira. A importância da ludicidade na construção do conhecimento. Revista Eletrônica Saberes da Educação, v. 5, n. 1, p. 1-16, 2014.

RIO DE JANEIRO. Deliberação CEE no 376, de 23 de março de 2020. Diário Oficial [do] Governo do Estado do Rio de Janeiro, Rio de Janeiro, 2020. Disponível em: http: //www.cee.rj.gov.br/deliberacoes/D_2020-376.pdf. Acesso em: 08 set. 2020.

SCHMITZ, Elieser Xisto da Silva. Sala de Aula Invertida: uma abordagem para combinar metodologias ativas e engajar alunos no processo de ensino-aprendizagem. 185f. 2016. Dissertação (Mestrado) - Universidade Federal de Santa Maria, Rio Grande do Sul, 2016.

VALENTE, José Armando. Blend learning e as mudanças no ensino superior: a proposta da sala de aula invertida. Educar em Revista, Scielo, n.SPE4, p.79-97, 2014.

VALENTE, José Armando; ALMEIDA, Maria Elizabeth Bianconcini de; GERALDINI, Alexandra Flogi Serpa. Metodologias ativas: das concepções às práticas em distintos níveis de ensino. Revista Diálogo Educacional, Pontifícia Universidade Católica do Paraná, v.17, n.52, p.455-478, 2017. 